\title{
Recovery from Phytotoxicity after Foliar Application of Fruit-loosening Abscission Compounds to Citrus
}

\author{
Kuo-Tan Li ${ }^{1}$, Jacqueline K. Burns ${ }^{2}$, and James P. Syvertsen \\ Horticultural Sciences Department, University of Florida, Institute of Food and Agricultural \\ Sciences, Citrus Research and Education Center, Lake Alfred, FL 33850
}

\begin{abstract}
AdDitional INDEX words. 5-chloro-3-methyl-4-nitro-1H-pyrazole, chlorophyll fluorescence, Citrus sinensis, ethephon, photosynthesis, sweet orange, water potential

Abstract. The use of abscission compounds to loosen fruit from stems can be accompanied with various levels of phytotoxicity. To determine the effects of a promising abscission compound, 5-chloro-3-methyl-4-nitro-1H-pyrazole (CMNP), and ethephon on sweet orange [Citrus sinensis (L.) Osbeck] leaf function, water relations, and young fruit growth, we sprayed CMNP at 0, 200, 500, 1000, or $2000 \mathrm{mg} \cdot \mathrm{L}^{-1}$ or ethephon at 400 or $800 \mathrm{mg} \cdot \mathrm{L}^{-1}$ to fruiting branches of potted and field-grown sweet orange during the 2005-06 harvest season. Both compounds induced abscission of mature fruit and leaves 3 days after application but had little effect on leaf chlorophyll content, water content, and midday leaf water potential $\left(\Psi_{\text {leaf }}\right)$ of remaining leaves. CMNP sprayed at $200 \mathrm{mg} \cdot \mathrm{L}^{-1}$ or either concentration of ethephon did not affect leaf photosystem II efficiency, as indicated by leaf chlorophyll fluorescence $(F v / F m)$. High CMNP concentrations (1000 or $\left.2000 \mathrm{mg} \cdot \mathrm{L}^{-1}\right)$ reduced $F v / F m 1$ day after treatment, but $F v / F m$ of leaves remaining on sprayed branches gradually recovered to the level of control leaves by 4 days after treatment. Similarly, high concentrations of CMNP and ethephon temporarily reduced net gas exchange of leaves for about 4 days. Young fruit growth also was temporarily inhibited by CMNP concentrations greater than $200 \mathrm{mg} \cdot \mathrm{L}^{-1}$. We conclude that CMNP sprayed at recommended concentrations $\left(200-500 \mathrm{mg} \cdot \mathrm{L}^{-1}\right)$ caused mature fruit abscission with little long-term phytotoxic effect on leaves or young fruit.
\end{abstract}

Concerns about the availability and rising cost of harvest labor have led Florida's citrus industry toward the adoption of mechanical harvesting (Brown, 2005). Apparent visible mechanical injuries during harvest have proven harmless to the citrus tree's overall physiological performance ( $\mathrm{Li}$ and Syvertsen, 2005; Li et al., 2005, 2006). The acreage of sweet orange (Citrus sinensis) in Florida harvested with a trunk or canopy shaker has continuously grown in recent years. However, mechanical harvest of late-maturing 'Valencia' oranges in May has been problematic because mature and immature fruit are present on the tree at the same time. Mechanical harvesting is abandoned after young 'Valencia' orange fruit reach a certain size to avoid removal of young fruit representing the next year's crop during harvesting. Reducing the intensity of the harvest machine to prevent green fruit removal during late season harvesting has shown to be impractical due to decreased efficiency of the harvesting operation. However, removal of mature and young green fruit could be differentiated by using fruit abscission compounds (Burns et al., 2006), provided the compounds are selective for mature fruit and nonphytotoxic.

Several abscission compounds that accelerate abscission by decreasing the detachment force of mature citrus fruit have been identified (Burns et al., 2003; Hartmond et al., 2000a,

Received for publication 3 Apr. 2008. Accepted for publication 29 Apr. 2008. This work was supported by UFL/IFAS and was partially funded by the Florida's Citrus Initiative Program.

Mention of a trademark does not imply endorsement of the product named or criticism of similar products not named.

We thank Drs. Tim Spann and Shiv Sharma for critical reviews. We also wish to acknowledge the excellent technical assistance of Dr. Luis Pozo.

${ }^{1}$ Current address: Department of Horticulture, National Taiwan University, Taipei, Taiwan 10617.

${ }^{2}$ Corresponding author. E-mail: jkbu@ufl.edu. 2000b; Kender et al., 1998; Yuan et al., 2002). Among these compounds, 5-chloro-3-methyl-4-nitro-1H-pyrazole has shown promise in terms of selectivity and uniformity of fruit loosening (Burns, 2002); furthermore, research has demonstrated increased mechanical harvesting efficiency when CMNP is used (Burns et al., 2005). Application of CMNP to citrus canopies did not decrease yield in multiyear trials (Whitney, 2003). Despite this fact, the paucity of information on shortand intermediate-term physiological effects of CMNP has been one of the major concerns of growers who must understand its impact and interaction with established citrus management strategies when CMNP registration is completed.

The mode of action of CMNP is currently unknown, but previous work has provided some information on reactions of leaves and fruit to CMNP and fundamental physiological responses. Temperatures below $15{ }^{\circ} \mathrm{C}$ for the first $24 \mathrm{~h}$ after application prevent fruit loosening (Yuan and Burns, 2004). When applied by soil drenching, CMNP can cause typical herbicide-like phytotoxic symptoms on leaves of various plants, including citrus (Alferez et al., 2005, 2006). Using foliar CMNP application, citrus leaves and immature fruit had no visual phytotoxic symptoms and did not abscise when used at a concentration that caused mature fruit abscission. At this CMNP concentration, limited physiological measurements showed marked effects in mature fruit, but not in leaves (Alferez et al., 2005; Yuan and Burns, 2004). Higher application rates, however, caused excessive leaf abscission (Burns, 2002), suggesting that CMNP was entering the leaf, but supraoptimal concentrations were necessary to overcome an unknown physiological impediment to efficacy.

Based on this physiological evidence, we hypothesized that citrus leaves and young fruit are capable of recovering 
from any potential phytotoxicity induced by a range of concentrations of foliar-applied CMNP. We measured the photosynthetic ability and water status of leaves of fruiting citrus trees to determine the effects of CMNP in comparison with ethephon, a commercially available abscission compound that often causes excessive defoliation and young fruit drop (Kender et al., 2000; Morton et al., 1978). We also determined the effect of CMNP and ethephon on young fruit retention and growth rate. Results provide useful information that may assist the ongoing commercial registration effort of CMNP as an abscission agent for citrus.

\section{Materials and Methods}

\section{Abscission compounds and application}

Similar treatments were applied in growth chamber and field experiments. Application rates of CMNP (17.2\% a.i.; Abbott Laboratories, Chicago) at 200, 500, 1000, or 2000 $\mathrm{mg} \cdot \mathrm{L}^{-1}(1.2,3.1,6.2$, and $12.3 \mathrm{~mm})$ and ethephon $(21.7 \%$ 2-chloro-2-ethyl-phosphonic acid; Ethrel ${ }^{\circledR}$; Aventis Crop Science, Research Triangle Park, NC) at 400 or $800 \mathrm{mg} \cdot \mathrm{L}^{-1}(2.8$ and $5.5 \mathrm{~mm}$ ) were chosen based on optimal and supraoptimal concentrations determined in previous work (Burns, 2002; Burns et al., 2005, 2006). Compounds were applied as foliar sprays to runoff. All spray solutions contained $0.125 \%$ of an adjuvant (proprietary mix of $25 \%$ organosilicone and $75 \%$ nonionic oil; Kinetic ${ }^{\circledR}$; Setre Chemical Co., Memphis, TN). Water plus adjuvant was sprayed on control treatments. In each trial, solutions were applied in late morning after the canopy had dried from any morning dew. Application dates were selected to ensure that no precipitation was forecasted within $8 \mathrm{~h}$ after spray.

\section{Growth chamber experiment}

An experiment in growth chambers was begun in Nov. 2005 using 6-year-old potted 'Hamlin' sweet orange (C. sinensis) trees grown on Swingle citrumelo [Citrus paradisi Macf. $\times$ Poncirus trifoliata (L.) Raf.] rootstock. Ten fruiting trees growing in 100-L containers were randomly assigned to two identical controlled environment growth chambers $2 \mathrm{~d}$ before spray treatments. The day/night temperature of the growth chambers was $28 / 20{ }^{\circ} \mathrm{C}$. The photoperiod was $16 \mathrm{~h}$ using photosynthetically active radiation of $1000 \mu \mathrm{mol} \cdot \mathrm{m}^{-2} \mathrm{~s}^{-1}$. Relative humidity inside the chamber was maintained within the range of $65 \%$ to $80 \%$. In one growth chamber, 15 uniform fruiting branches distributed among five trees were selected and randomly assigned to four CMNP and one control treatment $(n=$ three branches per treatment). In the other growth chamber, nine similar fruiting branches distributed among five trees were assigned to two ethephon treatments and the control. Each branch contained at least five fruit and 150 leaves. Abscission compounds were applied with 1-L pressurized spray bottles. Fruit and leaf retention and chlorophyll fluorescence were measured daily for $4 \mathrm{~d}$ as described below.

\section{Field trials}

Four field trials were conducted through the 2005-06 harvest season using healthy, uniform bearing trees grown at the University of Florida's Citrus Research and Education Center in Lake Alfred. In three trials, 14-year-old 'Hamlin' sweet orange trees on Carrizo citrange $(C$. sinensis $\times P$. trifoliata) rootstock were used. Trees were $3.5 \mathrm{~m}$ tall and were spaced at
$6.1 \mathrm{~m}$ between rows and $4.6 \mathrm{~m}$ within rows. The trunk diameter averaged $26 \mathrm{~cm}$ at $30 \mathrm{~cm}$ above the bud union. Sixteen uniform trees in two north-south rows were used. In the fourth trial, 16year-old 'Valencia' sweet orange trees on Swingle citrumelo rootstock were used. Trees were $3.5 \mathrm{~m}$ tall and were spaced at $4 \mathrm{~m}$ between rows and $2 \mathrm{~m}$ within rows. The trunk diameter averaged $36 \mathrm{~cm}$ at $30 \mathrm{~cm}$ above the bud union. Five trees in a north-south row were used. The soil type at all sites was Candler fine sand with low water holding capacity and organic matter $<1 \%$. Trees received normal irrigation, pest control, and fertilization.

'HAMlin' ORANGe FiELd TRIALS. Treatments were randomly assigned and applied to branches. On 16 Dec. 2005, 15 uniform branches distributed among five trees were randomly assigned to four CMNP and one control treatments $(n=3$ branches per treatment). On 20 Dec. 2005, nine branches distributed among four trees were selected and randomly assigned to two ethephon and one control treatments ( $n=3$ branches). These two companion trials were intended to be used as field comparisons for the two applications performed in the growth rooms as described above. On 7 Feb. 2006, 21 uniform branches were distributed among six trees and randomly assigned to six abscission compound (four CMNP and two ethephon rates) and one control treatments. In all trials, each branch contained $>80$ leaves and five to 10 mature fruit. All branches were chosen from the exposed east side of the tree rows and from the middle section of the canopy. Leaf and fruit retention was measured in all 'Hamlin' orange field trials. Leaf water content, leaf dry weight, midday leaf water potential, and leaf chlorophyll fluorescence and chlorophyll content were measured as described below and were monitored daily beginning $24 \mathrm{~h}$ after treatment for $4 \mathrm{~d}$ in the first two trials. For the third 'Hamlin' orange trial conducted on 7 Feb. 2006, measurements were made daily for $4 \mathrm{~d}$ after application, and then on days 7 and 10.

'VALENCIA' ORANGe Field TRIAL. On 23 May 2006, from six trees, a total of 21 branches were selected from the middle section of the east-face of 'Valencia' orange canopies and were randomly assigned to the treatments described above. Each branch had more than 80 leaves and at least three mature and three young fruit. Leaf and fruit retention, leaf chlorophyll fluorescence, and leaf gas exchange were monitored as described below after application of abscission compounds beginning at time 0 and continuing every 1 or $2 \mathrm{~d}$ for $7 \mathrm{~d}$. Young fruit growth was measured as described below.

\section{Fruit and leaf retention, and leaf water status}

Leaf retention was monitored on about 100 leaves within each experimental branch in 'Hamlin' orange trials, and on entire branches in the 'Valencia' orange trial. Numbers of leaves remaining on each branch were counted daily beginning at time 0 and continuing daily after treatments. The percentage of leaf retention was calculated by dividing the number of leaves retained on the branch by the total starting leaf number, and multiplying by 100 . In 'Hamlin' orange trials, five leaves were randomly sampled from each branch each day after treatment and leaf area, fresh weight, dry weight, leaf water content, and leaf dry weight to area (LDW:A) ratio were measured to determine leaf water status. The percentage of fruit retention was calculated by dividing the number of fruit retained on the branch by the total starting fruit number, and multiplying by 100 . 
Midday leaf water potential ( $\left.\Psi_{\text {leaf }}\right)$ measurements

Midday $\Psi_{\text {leaf }}$ was measured between 1330 and 1430 HR with a pressure chamber (Scholander et al., 1965). Two light-exposed mature leaves from the latest mature summer or spring flushes on each branch were used. Each leaf blade was sealed in an aluminum foil-covered plastic bag immediately before cutting the petiole to minimize water loss inside the pressure chamber.

\section{Leaf chlorophyll fluorescence measurements}

Chlorophyll fluorescence was measured with a pulse-modulated fluorometer (OS-1-FL; OptiScience, Tyngsboro, MA) between 1300 and 1330 HR. Two leaves from each branch were dark-adapted with leaf clips for at least $2 \mathrm{~h}$ prior to measurement to ensure that photosystem II reaction centers were in an active open status. The minimal fluorescence emission from the dark-adapted leaf area $\left(F_{o}\right.$, nomenclature from van Kooten and Snel, 1990) was excited by low $(<1$ $\left.\mu \mathrm{mol} \cdot \mathrm{m}^{-2} \cdot \mathrm{s}^{-1}\right)$ intensity-modulated 655-nm light and was detected in the 700- to 750-nm range. After $F_{o}$ was detected, the photosystem was saturated by a high-intensity $\left(\approx 15,000 \mu \mathrm{mol} \cdot \mathrm{m}^{-2} \cdot \mathrm{s}^{-1}, 350-690\right.$ $\mathrm{nm}$ ) light pulse for $0.85 \mathrm{~s}$ to induce maximal fluorescence from the dark-adapted leaf area $\left(F_{m}\right)$. Variable fluorescence from the dark-adapted leaf area $\left(F_{v}\right)$ was calculated from $\left(F_{m}-F_{o}\right)$ (van Kooten and Snel, 1990).

\section{Leaf chlorophyll content measurements}

Leaf chlorophyll content was measured daily after treatments using a procedure modified from Inskeep and Bloom (1985). Briefly, four $0.2-\mathrm{cm}^{2}$ leaf discs were removed from leaves sampled for leaf water content measurements. Chlorophyll was extracted from leaf discs in the dark with $2 \mathrm{~mL}$ N,N-dimethylformamide (DMF) for at least $72 \mathrm{~h}$. Absorbance of the chlorophyll-DMF solution was measured at 647 and $664 \mathrm{~nm}$ with a spectrophotometer (SmartSpec TM3000; Bio-Rad, Hercules, CA).

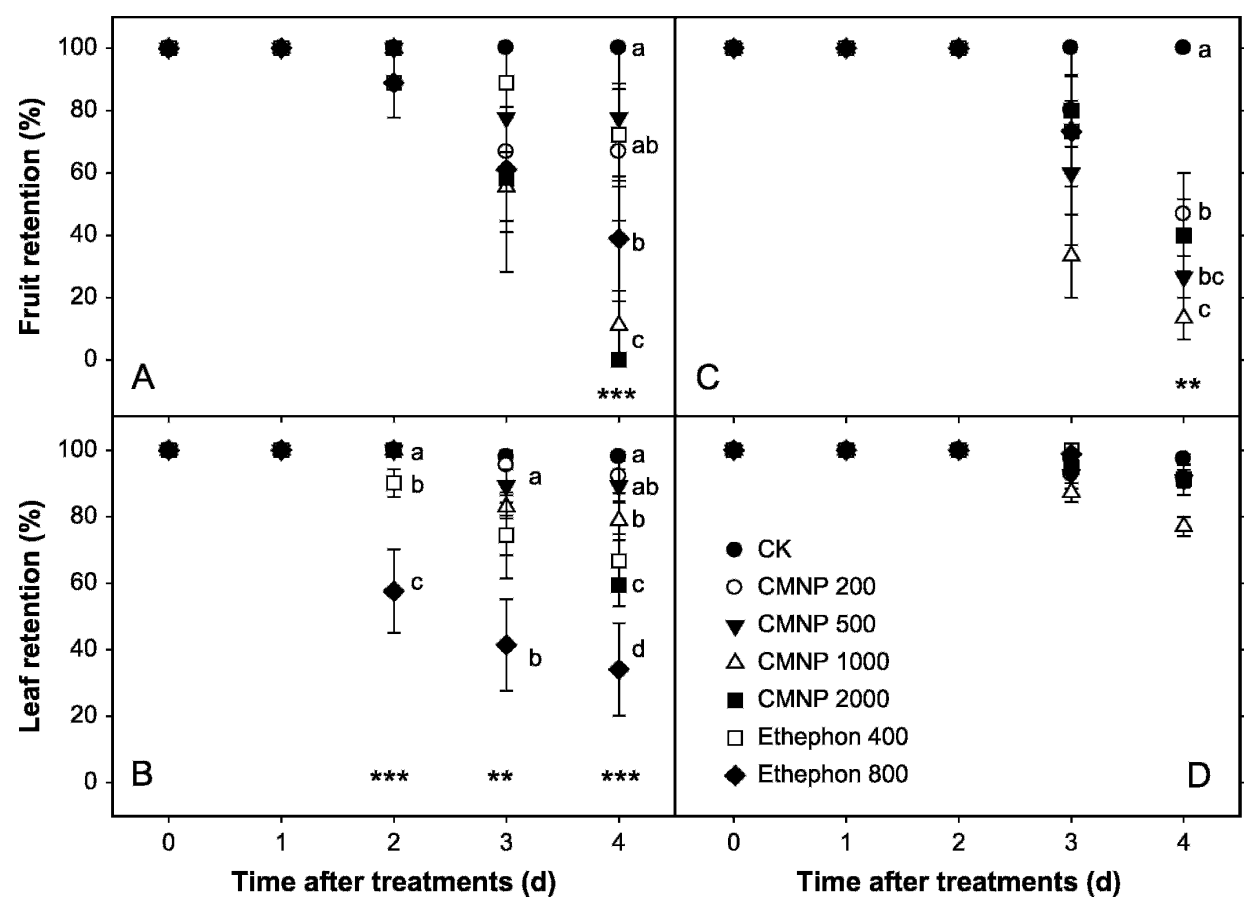

Fig. 1. Effects of 5-chloro-3-methyl-4-nitro-1H-pyrazole (CMNP) and ethephon on mature fruit (A and $\mathbf{C})$ and leaf retention (B and $\mathbf{D}$ ) in 'Hamlin' sweet orange fruiting branches. CMNP or ethephon at various concentrations $\left(\mathrm{mg} \cdot \mathrm{L}^{-1}\right.$ ) was sprayed on 3 Nov. and 8 Nov. 2005, respectively, in the growth chamber trial (A and B), and on 16 Dec. and 20 Dec. 2005, respectively, in the field trial (C and D). Controls (CK) were sprayed with water plus adjuvant only. Each symbol represents a mean of three branches in each treatment; vertical bars represent $\pm 1 \mathrm{SE}$. $*, * *$, and $* * *$ indicate significant difference at $P \leq 0.05,0.01$, and 0.001 , respectively. Mean separation by Duncan's multiple comparisons. CMNP 200, 500, 1000, and $2000=200,500,1000$, and $2000 \mathrm{mg} \cdot \mathrm{L}^{-1}$; Ethephon 400 and $800=400$ and $800 \mathrm{mg} \cdot \mathrm{L}^{-1}$.

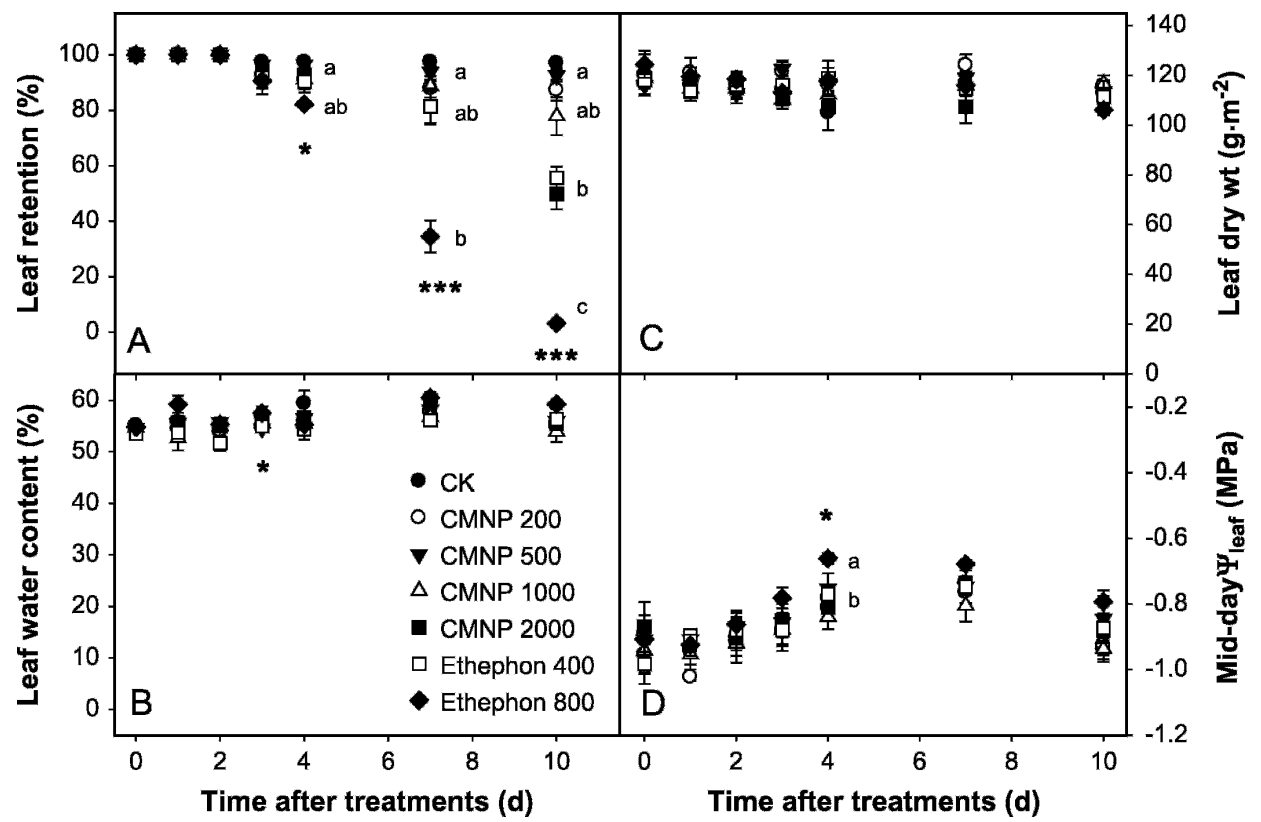

Fig. 2. Effects of 5-chloro-3-methyl-4-nitro-1H-pyrazole (CMNP) and ethephon on (A) leaf retention, (B) leaf water content, $(\mathbf{C})$ leaf dry weight per unit leaf area, and $(\mathbf{D})$ midday leaf water potential $\left(\Psi_{\text {leaf }}\right)$ in 'Hamlin' sweet orange fruiting branches. CMNP or ethephon at various concentrations $\left(\mathrm{mg} \cdot \mathrm{L}^{-1}\right)$ was sprayed on $7 \mathrm{Feb} .2006$. Controls (CK) were sprayed with water plus adjuvant only. Leaf water content and leaf dry weight/leaf area are means $(n=5)$ of five leaves sampled from three branches in each treatment. Midday $\Psi_{\text {leaf }}$ are means $(n=6)$ of two leaves on each of three branches. Vertical bars represent \pm 1 SE. *, **, and $* * *$ indicate significant difference at $P \leq 0.05,0.01$, and 0.001 , respectively. Mean separation by Duncan's multiple comparisons. CMNP 200, 500,1000 , and $2000=200,500,1000$, and $2000 \mathrm{mg} \cdot \mathrm{L}^{-1}$; Ethephon 400 and $800=400$ and $800 \mathrm{mg} \cdot \mathrm{L}^{-1}$. 
Chlorophyll content was expressed on a mass per unit area basis.

\section{Leaf gas exchange measurements}

Net gas exchange of leaves was measured daily between 0930 and 1100 HR after abscission compound treatments using a portable photosynthesis system (LI-6200; LI-COR, Lincoln, NE). Photosynthetically active radiation was between 400 and $600 \mu \mathrm{mol} \cdot \mathrm{m}^{-2} \cdot \mathrm{s}^{-1}$ during all measurement dates due to persisting overcast conditions after abscission compound application. Leaf temperature in the measurement cuvette was close to ambient air temperature (between 28 and $35{ }^{\circ} \mathrm{C}$ ). Relative humidity inside the cuvette was close to ambient relative humidity (between $50 \%$ and $70 \%$ ). Three healthy outer canopy mature leaves on each branch were evaluated throughout the experiment period. In a few cases, the labeled leaf abscised and an adjacent healthy leaf was used. Measurements were made on one leaf per treatment sequentially over time to ensure sampling across environmental conditions. Net assimilation of $\mathrm{CO}_{2}\left(\mathrm{~A}_{\mathrm{CO} 2}\right)$ and transpiration (E) were measured and stomatal conductance $\left(g_{\mathrm{S}}\right)$, and the ratio of internal-to-ambient $\mathrm{CO}_{2}(\mathrm{Ci} / \mathrm{Ca})$ was automatically calculated.

\section{Young fruit growth measurement}

One green fruit from each branch was labeled and the diameter was measured immediately before and $1 \mathrm{~d}$ after treatments, and then about every other day for $17 \mathrm{~d}$. Another measurement was made $45 \mathrm{~d}$ after application. At each sampling day, the relative fruit growth rate was calculated by measuring young fruit diameter, subtracting this value from its pretreatment diameter on 23 May 2006, dividing by the pretreatment diameter, and then multiplying by 100 .

\section{Experimental design and statistical analysis}

A completely randomized design with seven treatments and three replicates was used in this study. Each fruiting branch was an experimental unit. Data were subjected to analysis of variance. Arcsin transformation was applied on percentage data prior analysis but actual data are presented. For gas exchange and chlorophyll fluorescence measurements, subsamples within a branch were averaged before statistical analysis. Significance was determined at $P \leq 0.05,0.01$, or 0.001 and means were separated by Duncan's multiple comparisons.

\section{Results}

Fruit AND LEAF ABSCISSION, AND LEAF WATER STATUS. All concentrations of CMNP and ethephon effectively induced mature fruit drop $4 \mathrm{~d}$ after spray in 2005 growth chamber and field 'Hamlin' orange trials (Fig. 1, A and C, respectively). CMNP concentrations at or below $500 \mathrm{mg} \cdot \mathrm{L}^{-1}$ did not induce significant leaf abscission in comparison with the control (Fig. 1, B and D). However, significantly less leaves were retained on branches due to increased ethephon applications in the growth chamber trial (Fig. 1B). The rate and amount of defoliation was similar in the CMNP $2000 \mathrm{mg} \cdot \mathrm{L}^{-1}$ and ethephon $400 \mathrm{mg} \cdot \mathrm{L}^{-1}$ treatment. No significant defoliation was recorded in the 2005 field 'Hamlin' orange trials (Fig. 1D) even though all treatments effectively induced fruit abscission (Fig. 1C). As efficacy of ethephon is known to be reduced by temperatures below $10{ }^{\circ} \mathrm{C}$ (Yuan and Burns, 2004), the lack of leaf abscission was likely due to night temperatures below $10^{\circ} \mathrm{C}$ for 4 consecutive days after the 20 Dec. 2005 application.

Similar to the 2005 trials, CMNP at or below $500 \mathrm{mg} \cdot \mathrm{L}^{-1}$ caused significant fruit loss (data not shown) in the 2006 trials. CMNP at $2000 \mathrm{mg} \cdot \mathrm{L}^{-1}$ and ethephon at $400 \mathrm{mg} \cdot \mathrm{L}^{-1}$ induced similar but higher leaf loss $10 \mathrm{~d}$ after application when compared with the control, and ethephon at $800 \mathrm{mg} \cdot \mathrm{L}^{-1}$ resulted in complete defoliation (Fig. 2A). Regardless of defoliation rate, leaf water content (Fig. 2B) and leaf dry weight-to-leaf area ratio (Fig. 2C) were mostly unchanged in retained 'Hamlin' orange leaves after application of abscission compounds. There was also no significant difference on $\Psi_{\text {leaf }}$ among all treatments, except that ethephon at $800 \mathrm{mg} \cdot \mathrm{L}^{-1}$ improved $\Psi_{\text {leaf }}$ of the remaining leaves $4 \mathrm{~d}$ after treatment (Fig. 2D).

LEAF CHLOROPHYLL CONTENT AND CHLOROPHYLL FLUORESCENCE. In the 2006 'Hamlin' orange trial, neither abscission compound affected leaf chlorophyll contents at
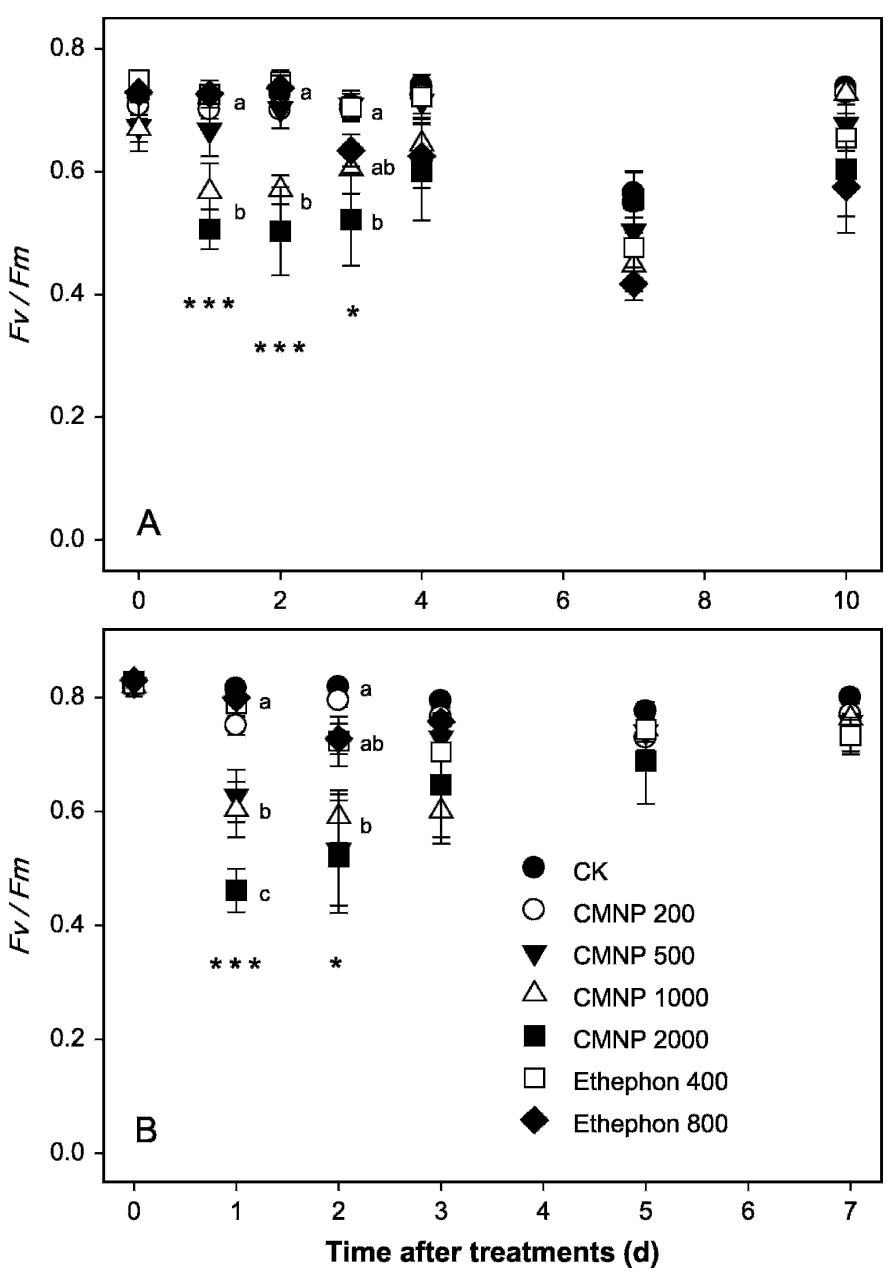

Fig. 3. Effects of 5-chloro-3-methyl-4-nitro-1H-pyrazole (CMNP) and ethephon on leaf chlorophyll fluorescence $\left(F_{v} / F_{m}\right)$ in (A) 'Hamlin' and (B) 'Valencia' sweet orange leaves. CMNP or ethephon at various concentrations (mg. $\mathrm{L}^{-1}$ ) was sprayed on 7 Feb. 2006 in 'Hamlin' and on 23 May 2006 in 'Valencia' sweet orange. Controls (CK) were sprayed with water and adjuvant only. Each symbol represents the mean $(n=6)$ of two leaves from each of three branches; vertical bars represent $\pm 1 \mathrm{SE} . *, * *$, and *** indicate significant difference at $P \leq 0.05,0.01$, and 0.001 , respectively. Mean separation by Duncan's multiple comparisons. CMNP 200, 500, 1000, and 2000 $=200,500$, 1000 , and $2000 \mathrm{mg} \cdot \mathrm{L}^{-1}$; Ethephon 400 and $800=400$ and $800 \mathrm{mg} \cdot \mathrm{L}^{-1}$. 
any sampling day. Leaf chlorophyll $a$ was maintained at 0.25 $\mathrm{g} \cdot \mathrm{m}^{-2}$, chlorophyll $b$ at $0.2 \mathrm{~g} \cdot \mathrm{m}^{-2}$, and total leaf chlorophyll at $0.45 \mathrm{~g} \cdot \mathrm{m}^{-2}$ (data not shown).

Leaf chlorophyll fluorescence, however, responded to CNMP and ethephon applications differently. Significant reductions in $F v / F m$ were measured with 1000 and $2000 \mathrm{mg} \cdot \mathrm{L}^{-1}$ CMNP applications by 1 and $2 \mathrm{~d}$ after application (Fig. 3A). After this time, $F v / F m$ increased in leaves treated with these CMNP applications until by day 4, chlorophyll fluorescence was no different from control leaves. In contrast, ethephon applications had no significant effect on $F v / F m$ in leaves remaining on treated branches. Similar trends were measured in 'Hamlin' orange trees in the 2005 growth chamber study, except that CMNP-induced reduction in $F_{v} / F_{m}$ was detectable $6 \mathrm{~h}$ after application (data not shown). Thus, CMNP-induced reductions in leaf fluorescence parameters were temporary, as leaves recovered by $4 \mathrm{~d}$ after application.

Similar trends were obtained in 'Valencia' orange (Fig. 3B); however, leaves appeared to be more sensitive to CMNP, possibly due to a cultivar effect or younger leaf age than those in 'Hamlin' orange trials. CMNP at $500 \mathrm{mg} \cdot \mathrm{L}^{-1}$ induced a significant reduction in $F_{v} / F_{m}$. Like 'Hamlin' orange, the reduction in $F v / F m$ in 'Valencia' orange leaves was temporary and leaves recovered to controls levels by $4 \mathrm{~d}$ after application.

LEAF GAS EXCHANGE. In 'Valencia' orange leaves, CMNP application at $200 \mathrm{mg} \cdot \mathrm{L}^{-1}$ showed little effect on $\mathrm{A}_{\mathrm{CO} 2}, \mathrm{~g}_{\mathrm{s}}$, and $\mathrm{E}$ (Fig. 4, A-C). CMNP concentrations equal to or greater than $500 \mathrm{mg} \cdot \mathrm{L}^{-1}$ immediately reduced $\mathrm{A}_{\mathrm{CO} 2}, g_{\mathrm{S}}$, and $\mathrm{E} 1 \mathrm{~d}$ after treatment. However, similar to leaf chlorophyll fluorescence, these major gas exchange parameters recovered to control levels $4 \mathrm{~d}$ after treatment. Although ethephon at either concentration did not alter leaf chlorophyll fluorescence, $\mathrm{A}_{\mathrm{CO} 2}, g_{\mathrm{S}}$ and E were significantly reduced $1 \mathrm{~d}$ after application. $\mathrm{A}_{\mathrm{CO} 2}$ and $\mathrm{E}$ of $400 \mathrm{mg} \cdot \mathrm{L}^{-1}$ ethephon-treated leaves partially recovered by $2 \mathrm{~d}$ after treatment, but were numerically lower than those of control leaves and CMNP treatments $6 \mathrm{~d}$ after treatment (not significant). It was not possible to measure leaf gas exchange on $800 \mathrm{mg} \cdot \mathrm{L}^{-1}$ ethephontreated leaves after $4 \mathrm{~d}$ due to complete defoliation. $\mathrm{Ci} / \mathrm{Ca}$ of leaves after ethephon and $\geq 500$ $\mathrm{mg} \cdot \mathrm{L}^{-1} \mathrm{CMNP}$ treatments was significantly greater than that of the control and $200 \mathrm{mg} \cdot \mathrm{L}^{-1} \mathrm{CMNP}$ treatments $1 \mathrm{~d}$ after treatment (Fig. 4D).

Young Fruit Growth. CMNP at $200 \mathrm{mg} \cdot \mathrm{L}^{-1}$ had no effect on 'Valencia' orange young fruit growth (Fig. 5). However, growth was suppressed by CMNP at 500 to 1000 $\mathrm{mg} \cdot \mathrm{L}^{-1}$ for $10 \mathrm{~d}$, and then growth rate slowly recovered. Young fruit growth was completely stopped by CMNP at $2000 \mathrm{mg} \cdot \mathrm{L}^{-1} 3 \mathrm{~d}$ after treatment and there was no recovery of growth after $20 \mathrm{~d}$. However, after $45 \mathrm{~d}$, young fruit growth rate recov- ered to near control levels in all CMNP treatments. Ethephon spayed at 400 or $800 \mathrm{mg} \cdot \mathrm{L}^{-1}$ stopped young fruit growth and caused severe abscission such that measuring fruit growth was discontinued after $5 \mathrm{~d}$.

\section{Discussion}

Much work has been done to explore the efficacy of CMNP on mature citrus fruit, but little has been published on shortand long-term effects on citrus leaves and young fruit. This work explored the response of leaves and young fruit growth to CMNP, and compared these responses to a standard abscission compound, ethephon. Ethephon can effectively induce mature citrus abscission, but it often causes severe defoliation and young fruit drop. In addition, effects of ethephon are highly variable and temperature dependent (Yuan and Burns, 2004). These disadvantages have limited the potential of ethephon to the citrus industry. CMNP, with its high selectivity, is currently undergoing the process of commercial registration. When CMNP was applied on citrus canopies at the recommended concentration of 200 to $500 \mathrm{mg} \cdot \mathrm{L}^{-1}$, it consistently promoted mature fruit abscission and had little effect on leaves and young fruit (Burns, 2002). Ethephon and CMNP application caused ethylene evolution in responding tissues such as citrus fruit (Burns et al., 2003; Wilson, 1973; Yuan and Burns, 2004). However, other factors unique to each compound are likely to contribute to the differential response. In addition to the differences in defoliation and other visual injuries between CMNP and ethephon, our study shows that foliar application of these two compounds to citrus trees resulted in fruit and leaf loss, but different physiological reactions. When used as abscission agents, mature fruit respond to ethephon and CMNP

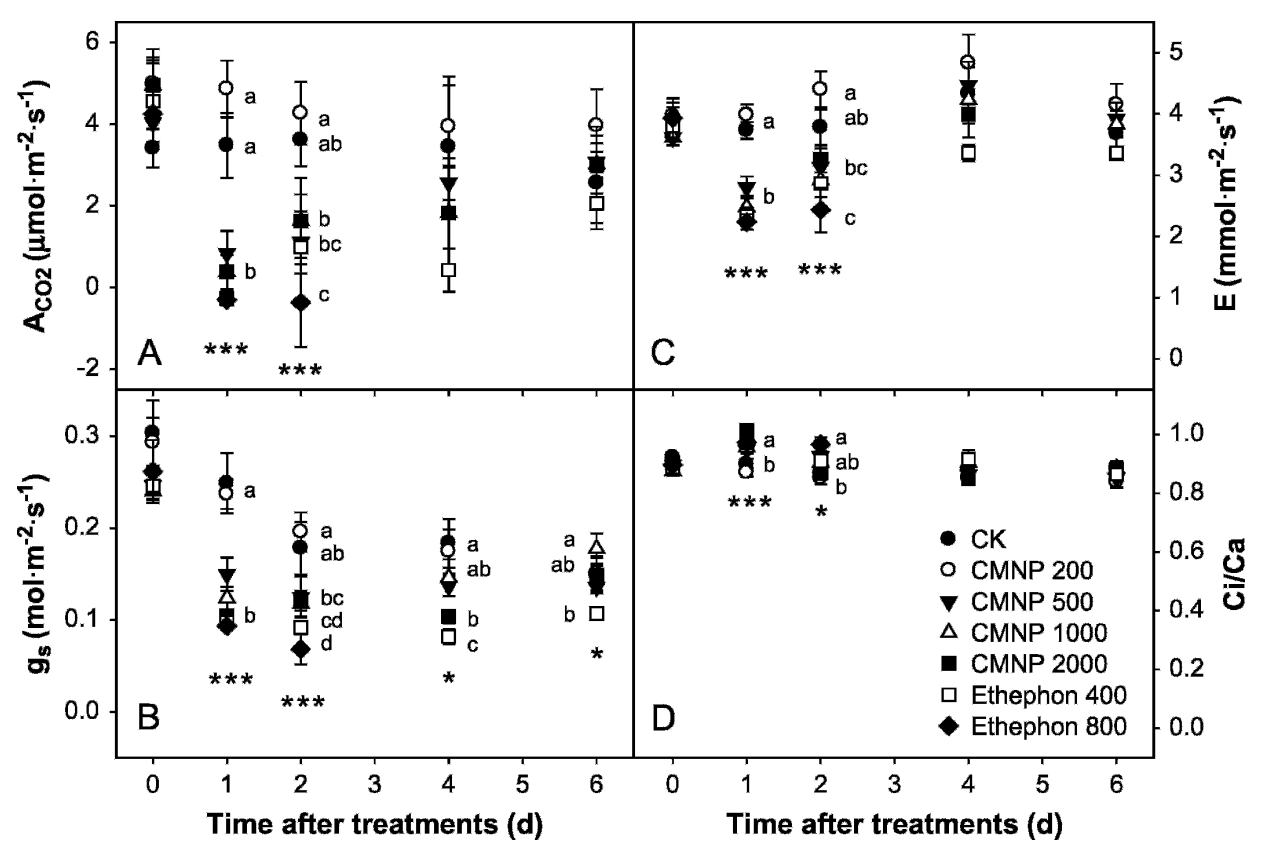

Fig. 4. Effects of 5-chloro-3-methyl-4-nitro-1H-pyrazole (CMNP) and ethephon on leaf gas exchange parameters: (A) $\mathrm{CO}_{2}$ assimilation $\left(\mathrm{A}_{\mathrm{CO} 2}\right),(\mathbf{B}) g_{\mathrm{S}},(\mathbf{C})$ transpiration $(\mathrm{E})$, and (D) internal to ambient $\mathrm{CO}_{2}$ ratio $(\mathrm{Ci} / \mathrm{Ca})$ in 'Valencia' sweet orange leaves. CMNP or ethephon at various concentrations $\left(\mathrm{mg} \cdot \mathrm{L}^{-1}\right)$ was sprayed on $23 \mathrm{May}$ 2006. Controls (CK) were sprayed with water and adjuvant only. Each symbol represents the mean $(n=6)$ of two leaves from each of three branches; vertical bars represent $\pm 1 \mathrm{SE} . *, * *$, and $* * *$ indicate significant difference at $P \leq 0.05,0.01$, and 0.001, respectively. Mean separation by Duncan's multiple comparisons. CMNP 200, 500, 1000 , and $2000=200,500,1000$, and $2000 \mathrm{mg} \cdot \mathrm{L}^{-1}$; Ethephon 400 and $800=400$ and $800 \mathrm{mg} \cdot \mathrm{L}^{-1}$. 


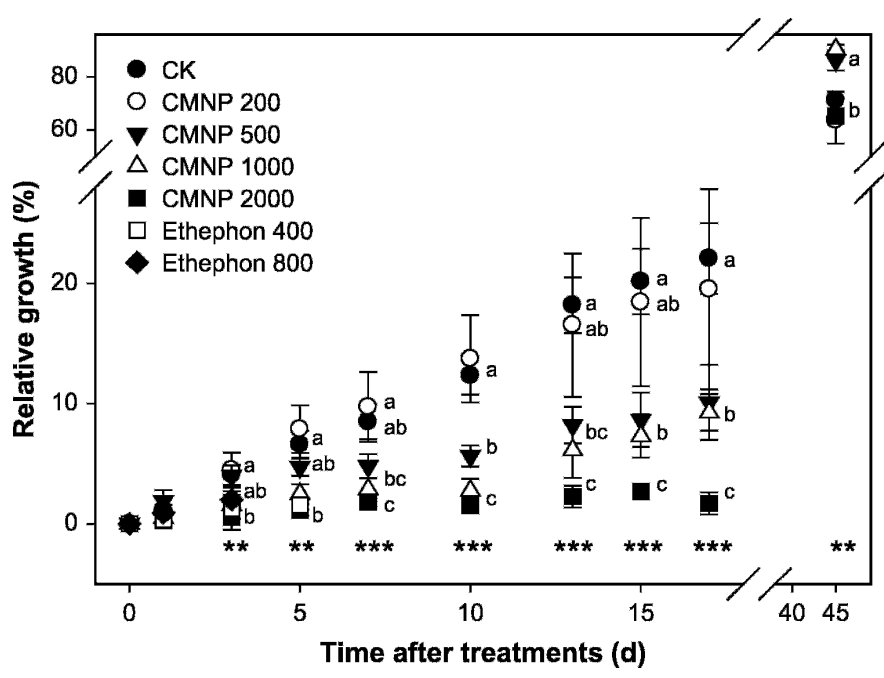

Fig. 5. Effect of 5-chloro-3-methyl-4-nitro-1H-pyrazole (CMNP) and ethephon on young fruit growth in 'Valencia' sweet orange. CMNP or ethephon at various concentrations $\left(\mathrm{mg} \cdot \mathrm{L}^{-1}\right)$ was sprayed on 23 May 2006. Controls $(\mathrm{CK})$ were sprayed with water and adjuvant only. Each symbol represents the mean $(n=3)$ of one fruit from each of three branches; vertical bars represent \pm 1 SE. $*$, **, and *** indicate significant difference at $P \leq 0.05,0.01$, and 0.001 , respectively. Mean separation by Duncan's multiple comparisons. CMNP $200,500,1000$, and $2000=200,500,1000$, and $2000 \mathrm{mg} \cdot \mathrm{L}^{-1}$; Ethephon 400 and $800=400$ and $800 \mathrm{mg} \cdot \mathrm{L}^{-1}$.

by causing fruit drop, reducing chlorophyll content, and changing peel color (Alferez et al., 2006). The present study showed that the degreening process did not occur in leaves, as chlorophyll content was unaffected by either compound regardless of the concentrations used. In addition, ethephon and CMNP did not affect leaf water content or leaf water potential. Therefore, visible leaf curling phenomenon occasionally observed after ethephon and CMNP spray appears not to be related to leaf water status. Moreover, stomatal closure is indicated by reduced $g_{\mathrm{S}}$ after application of CMNP or ethephon. Stomatal closure is likely attributable to the action of ethylene (Desikan et al., 2006) released from ethephon or generated by the plant after CMNP application (Yuan and Burns, 2004).

CMNP is lipid and water soluble (Alferez et al., 2005) and is presumed to be readily absorbed in plant tissues. Our data support the idea that CMNP enters the leaf, but the physiological consequences are transient when applied at concentrations used to accelerate mature fruit abscission. CMNP caused temporary effects on leaf gas exchange and chlorophyll fluorescence. Applications of high CMNP concentrations decreased leaf $\mathrm{A}_{\mathrm{CO} 2}$ and altered leaf chlorophyll fluorescence, suggesting that the negative effects of high CMNP concentrations on leaf gas exchange were at least partially a result of a temporary disturbance of membrane integrity or electron transport through photosystem II (Roháček and Barták, 1999). Inactivation of photosystem II is a general reaction of leaves to some herbicides or other phytotoxic compounds (Chow et al., 1989). CMNP was shown to act as an uncoupler of reactions associated with energetic membranes; however, a transient reduction of total cellular ATP that occurred in citrus fruit peel (Alferez et al., 2005) indicated that this CMNP effect was also temporary in mature fruit. On the other hand, although ethephon reduced leaf $\mathrm{A}_{\mathrm{CO} 2}$, it did not affect photosystem II efficiency, as indicated by unaltered leaf chlorophyll fluorescence parameters. Therefore, the negative impact on net $\mathrm{A}_{\mathrm{CO} 2}$ and significant increases in $\mathrm{Ci} / \mathrm{Ca}$ after ethephon treatment were more likely the results of other changes in leaf biochemistry, or perhaps due to increases in dark respiration, as was found in apple trees sprayed with ethephon (Untiedt and Blanke, 2001). The closure of stomata, as indicated by significantly lower $g_{s}$ and $\mathrm{E}$, was due to the increased $\mathrm{Ci} / \mathrm{Ca}$.

Similar to leaves, young citrus fruit growth was unaffected by the recommended CMNP concentration $\left(200 \mathrm{mg} \cdot \mathrm{L}^{-1}\right)$ that was adequate to induce mature fruit abscission. The cessation of fruit growth by high concentrations of CMNP may have been the result of a temporary shortage of ATP due to uncoupling (Alferez et al., 2005), partial defoliation, or suppression of leaf photosynthesis. Our fruit growth data support the idea that the delay of growth was compensated for after the functional recovery of old leaves and the regrowth of new leaves, or recovery of ability to supply ATP due to CMNP inactivation or other mechanisms.

\section{Conclusions}

Leaf abscission and phytotoxic responses occurred after foliar sprays of abscission compounds. Although ethephon and CMNP are effective abscission agents for mature citrus fruit, they appeared to affect citrus leaves and young fruit through different physiological mechanisms. At concentrations used on healthy, well-managed trees, ethephon had less of a negative impact on physiological functions of surviving citrus leaves than CMNP. However, ethephon caused severe defoliation and young fruit drop. CMNP, on the other hand, when used at recommended concentrations, appeared relatively safe to leaves and young fruit. Even at unacceptably high concentrations, CMNP induced less defoliation and young fruit drop than ethephon. Although at high concentrations CMNP caused more physiological injuries to citrus leaves than ethephon, these negative effects were temporary and diminished over time. The results provide physiological evidence that CMNP enters the leaf but its physiological action is transient, perhaps due to detoxification reactions that involve conversion to inactive products or internal compartmentation (Coleman et al., 1997). There may be a number of explanations for the differential effect of CMNP on fruit and leaves, including differences in uptake, target number, and detoxification rate. Whatever the mechanism, our results demonstrate CMNP can be an effective, selective, and relatively safe abscission compound for citrus.

\section{Literature Cited}

Alferez, F., L. Pozo, and J.K. Burns. 2006. Physiological changes associated with senescence and abscission in mature citrus fruit induced by 5-chloro-3-methyl-4-nitro- $1 \mathrm{H}$-pyrazole and ethephon application. Physiol. Plant. 127:66-73.

Alferez, F., S. Singh, A.L. Umbach, B. Hockema, and J.K. Burns. 2005. Citrus abscission and Arabidopsis plant decline in response to 5-chloro-3-methyl-4-nitro- $1 \mathrm{H}$-pyrazole are mediated by lipid signaling. Plant Cell Environ. 28:1436-1449.

Brown, G.K. 2005. New mechanical harvesters for the Florida citrus juice industry. HortTechnology 15:69-72.

Burns, J.K. 2002. Using molecular biology tools to identify abscission materials for citrus. HortScience 37:459-464.

Burns, J.K., R.S. Buker, and F.M. Roka. 2005. Mechanical harvesting capacity in sweet orange is increased with an abscission agent. HortTechnology 15:758-765. 
Burns, J.K., L.V. Pozo, R. Yuan, and B. Hockema. 2003. Guanfacine and clonidine reduce defoliation and phytotoxicity associated with abscission agents. J. Amer. Soc. Hort. Sci. 128(1): 42-47.

Burns, J.K., F.M. Roka, K.-T. Li, L. Pozo, and R.S. Buker. 2006. Late-season 'Valencia' orange mechanical harvesting with an abscission agent and low-frequency harvesting. HortScience 41(3):660-663.

Chow, W.S., C.B. Osmond, and L.K. Huang. 1989. Photosystem II function and herbicide binding sites during photoinhibition of spinach chloroplasts in vivo and in vitro. Photosyn. Res. 21:15731579.

Coleman, J.O.D., M.M.A. Blake-Kalff, and T.G.E. Davies. 1997. Detoxification of xenobiotics by plants: Chemical modification and vacuolar compartmentation. Trends Plant Sci. 2:144-151.

Desikan, R., K. Last, R. Harrett-Williams, C. Tagliavia, K. Harter, R. Hooley, J.T. Hancock, and S.J. Neill. 2006. Ethylene-induced stomatal closure in Arabidopsis occurs via AtrbohF-mediated hydrogen peroxide synthesis. Plant J. 47:907-916.

Hartmond, U., J.D. Whitney, J.K. Burns, and W.J. Kender. 2000a. Seasonal variation in the response of 'Valencia' orange to two abscission compounds. HortScience 35(2):226-229.

Hartmond, U., R. Yuan, J.K. Burns, A. Grant, and W.J. Kender. 2000 b. Citrus fruit abscission induced by methyl-jasmonate. J. Amer. Soc. Hort. Sci. 125(5):547-552.

Inskeep, W.P. and P.R. Bloom. 1985. Extinction coefficients of chlorophyll a and $\mathrm{b}$ in $\mathrm{N}, \mathrm{N}$-dimethylformamide and $80 \%$ acetone. Plant Physiol. 77:483-485.

Kender, W.J., U. Hartmond, M. Salyani, J.K. Burns, and J.D. Whitney. 1998. Effects of concentration and application time of 'Prosulfuron' on the abscission of 'Hamlin' and 'Valencia' oranges. Proc. Florida State Hort. Soc. 111:108-112.

Kender, W.J., U. Hartmond, R. Yuan, L. Pozo, and A. Grant. 2000. Factors influencing the effectiveness of ethephon as a citrus fruit abscission agent. Proc. Florida State Hort. Soc. 113:88-92.
Li, K.-T. and J.P. Syvertsen. 2005. Mechanical harvesting has little effect on water potential and leaf gas exchange in citrus trees. J. Amer. Soc. Hort. Sci. 130(5):661-666.

Li, K.-T., J.P. Syvertsen, and J.K. Burns. 2005. Mechanical harvesting of Florida citrus trees has little effect on leaf water relation or return bloom. Proc. Florida State Hort. Sci. 118:22-24.

Li, K.-T., J.P. Syvertsen, and J. Dunlop. 2006. Defoliation after harvest with a trunk shaker does not affect canopy light interception in citrus trees. Proc. Florida State Hort. Sci. 119:187-189.

Morton, C.C., O.L. Jahn, R.H. Young, and R.H. Biggs. 1978. Ethephon-induced defoliation patterns and subsequent yields in citrus. J. Amer. Soc. Hort. Sci. 103(5):670-673.

Roháček, K. and M. Barták. 1999. Technique of the modulated chlorophyll fluorescence: Basic concepts, useful parameters, and some applications. Phytosynthetica 37:339-363.

Scholander, P.F., E.D. Bradstreet, E.A. Hemmingsen, and H.T. Hammel. 1965. Negative hydrostatic pressure can be measured in plants. Science 148:339-346.

Untiedt, R. and M. Blanke. 2001. Effects of fruit thinning agents on apple tree canopy photosynthesis and dark respiration. Plant Growth Regulat. 35:1-9.

van Kooten, O. and J.F.H. Snel. 1990. The use of chlorophyll fluorescence nomenclature in plant stress physiology. Photosyn. Res. 25:147-150.

Whitney, J.D. 2003. Trunk shaker and abscission chemical effects on yields, fruit removal, and growth of orange trees. Proc. Florida State Hort. Soc. 116:230-235.

Wilson, W.C. 1973. Problems encountered using cycloheximide to produce abscission of oranges. HortScience 8:323-324.

Yuan, R. and J.K. Burns. 2004. Temperature factor affecting the abscission response of mature fruit and leaves to CMN-pyrazole and ethephon in 'Hamlin' oranges. J. Amer. Soc. Hort. Sci. 129:287-293.

Yuan, R., U. Hartmond, and W.J. Kender. 2002. Naphthalene acetic acid and 2,3,5-triiodobenzoic acid affect the response of mature orange fruit to abscission chemical. HortScience 37(2):348-352. 